\title{
VITAL STATISTICS FOR LEADING COUNTRIES IN COVID-19 CASES
} $\begin{array}{ll}\text { Zorawar Singh } & \text { Department of Zoology, Khalsa College Amritsar, Punjab, India. } \\ \text { Email: zorawarsinghs@rediffmail.com Tel: }+91-9417230075\end{array}$

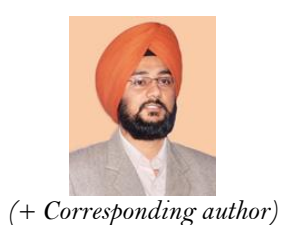

\begin{abstract}
Coronavirus disease (COVID-19) is an infectious disease caused by a newly discovered coronavirus and the overall number of the COVID-19 cases is increasing worldwide. As on 24th March, 2020, China, Italy and United States were found to be the countries with maximum number of reported cases. China seemed to manage this outbreak with only 3,281 deaths for 81,218 cases with a death rate of 0.040 and a recovery record of 73,650 patients. The present review emphasizes the comparative patterns with which this pandemic spread in the above mentioned three countries. Paper also discusses total cases, daily recorded cases and total deaths of patients with daily death records. Conclusively, COVID-19 is affecting the population globally at a very rapid rate and should be dealt with maximum efforts by all the countries.
\end{abstract}

\section{Keywords \\ Coronavirus \\ COVID-19 \\ Mortality rate \\ Deaths \\ WHO \\ Statistics.}

Contribution/Originality: This study documents the comparative patterns with which this pandemic spread among the leading countries including China, Italy and United States of America. The present paper also discusses total cases, daily recorded cases and total deaths of patients with daily death records.

\section{INTRODUCTION}

Talking of epidemics and pandemics, we can think of various events like Russian plague in 1770s, Yellow fever epidemic in 1793, Flu pandemic in 1890 and 1920, Asian flu in 1958, HIV pandemic in 1981, H1N1 Swine flu pandemic in 2009, Ebola epidemic 2014, Zika virus epidemic in 2015 and now we have a new epidemic of Coronavirus. On March 11th, 2020, WHO officially changed the designation of COVID-19 from an epidemic to a pandemic. Experts who have monitored health hazards at the Hajj for over 15 years, recommend that Hajj 2020 will be at risk of being suspended, especially if the situation with COVID-19 continues to escalate globally in the same way. The same holds true for the Summer 2020 Olympics in Japan [1].

The beginning of 2020 has seen the emergence of Coronavirus disease (COVID-19) outbreak caused by a novel coronavirus, Severe Acute Respiratory Syndrome Coronavirus 2 (SARS-CoV-2). COVID-19 has been identified as the cause of an outbreak of respiratory illness in Wuhan, China which began in December 2019 [2]. As on March $25^{\text {th }}$, 2020, this epidemic had spread with 438,717 confirmed cases, including 19,658 deaths and 111,926 recoveries. The World Health Organization (WHO) has declared it a public health emergency of international concern. There is an imminent need to better understand this new virus and to develop ways to control its spread. There are a number of recent research papers published related to COVID-19 [2-10]. Statistics on any disease are a vital index to better understand the spread and develop control strategies accordingly. The present paper reviews the statistics 
of the world's three leading countries in having the highest number of COVID-19 cases till March 22, 2020 which includes China, Italy and United States.

\subsection{Global COVID-19 Cases}

The overall number of the COVID-19 cases is ever increasing worldwide with 438,717 cases as on March 25, 2020 at 13:40 GMT. Total death toll is reaching 20,000. The current active cases include 307,133 infected patients out of which 293,855 (96\%) are in mild condition where as 13,278 (4\%) are considered to be critical. The total closed cases include 131, 584 cases with an outcome out of which 111,926 cases are discharged with 19,658 deaths. Figure 1 shows the number of COVID-19 cases with respect to number of patients demonstrated with a blue colour. Darker colour points out larger number of COVID-19 patients.

If the progression of total coronavirus cases is seen, it is revealed that there was a mild increase in the number of cases from January 22 to March 14, 2020. This increase was from 580 cases to 156,475 (155895 cases) in 53 days with an average of 2941.4 cases/day. But from March 15, 2020 onwards, this increase was seen to be very steep from 169,517 to 438,717 (269200 cases) in just 11 days with an average of 24472.7 cases/day worldwide. This is the reason why this virus is important to work on.

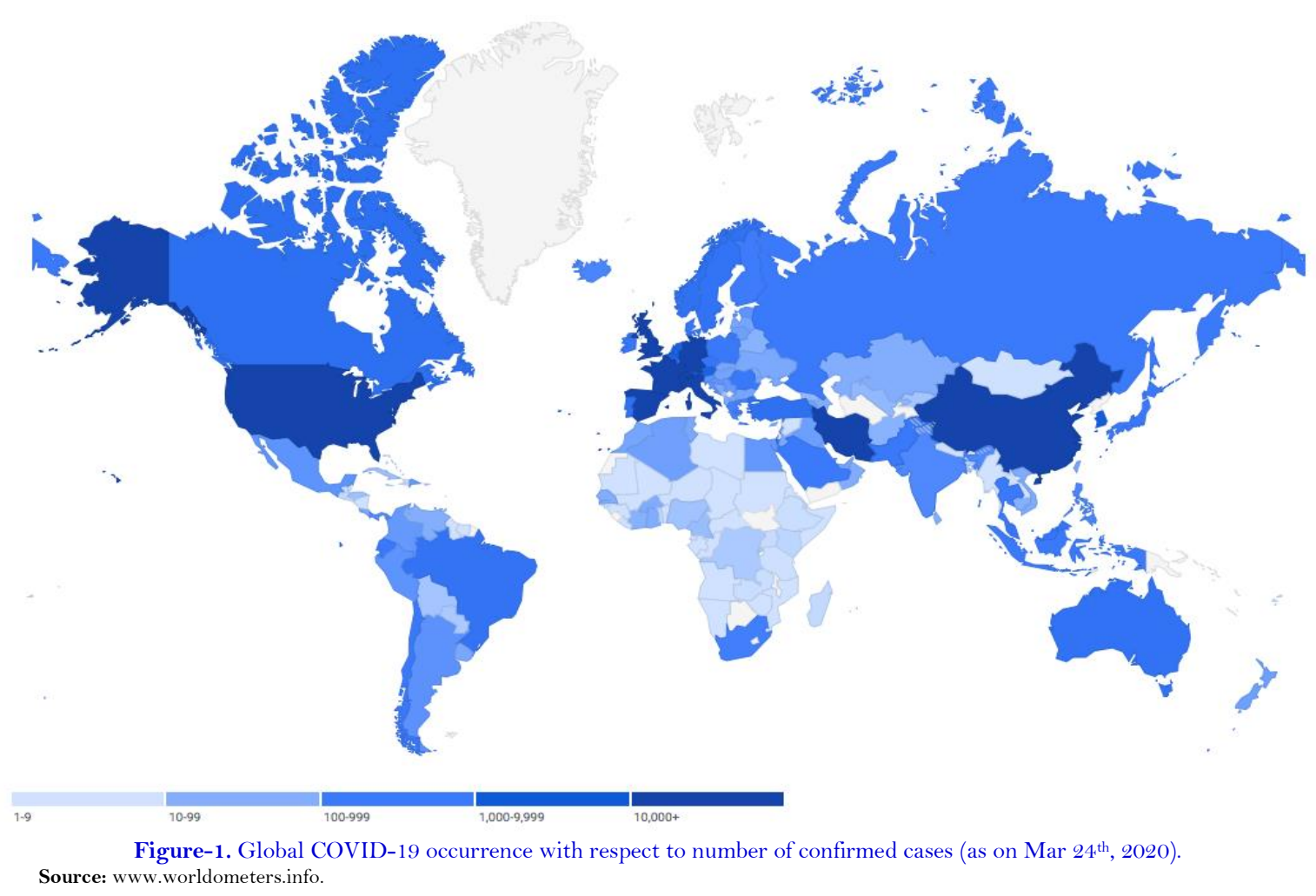

\subsection{Global Mortality Rates}

Initially, WHO had mentioned an estimate of $2 \%$ mortality rate on January 29, 2020 and again on February 10, 2020. However, on January 29, WHO specified that this was a very early and provisional estimate that might change. Surveillance was increasing, not only within China but also globally. As on February $20^{\text {th }}, 2020$ a total of 2,114 of the 55,924 laboratory confirmed cases had died which revealed a crude fatality ratio of 3.8 which was alarming. On March $3^{\text {rd }}$, 2020, WHO reported the mortality rate to be $3.4 \%$ [11]. Whereas in China, as on February 20, 2020 mortality rate was $5.8 \%$ in Wuhan, where it started, and $0.7 \%$ in other nearby areas. 
Table-1. Comparison of global death rates between COVID-19, SARS, MERS and Swine flu.

\begin{tabular}{l|c}
\hline Virus & Global death rate \\
\hline Wuhan Novel Coronavirus (2019-nCoV) & $3.4 \%^{*}$ \\
\hline SARS & $9.6 \%$ \\
\hline MERS & $34 \%$ \\
\hline Swine Flu & $0.02 \%$ \\
\hline Note: *As on March 3, 2020 (WHO).
\end{tabular}

A brief comparison of global mortality rates between COVID-19 and related SARS, MERS and Swine flu virus reveals that COVID-19 is less mortal than MERS and SARS. MERS showed the highest mortality rate of $34 \%$ followed by $9.6 \%$ by SARS whereas COVID-19 as on March 3, 2020 has been recorded with a mortality rate of 3.4\% Table 1.

\section{COMPARISON BETWEEN CHINA, ITALY AND UNITED STATES}

\subsection{Total COVID Cases}

Numbers are quickly rising. In China, the number of COVID-19 cases increased from January 22 to 28 at a medium pace from where the cases increased at a much higher rate until February 11, but as evident from the Figure 2 , the number of cases took a hike on February 12 to 18. After that the number of cases increased to 81,218 as on March 25, 2020 [12]. If we see the increase in the number of COVID-19 cases in Italy, we can pin-point February 12. After this point there was an exponential growth in the number of cases which reached the point of 69,176 . On the other hand, United States managed to keep the cases to the low level until March 16. But after that the number of COVID-19 cases increased at a very fast rate to reach 54,916. In this time (between March 16 till 25), the number of cases increased from 4,434 to 54,916 (50482 new cases detected).

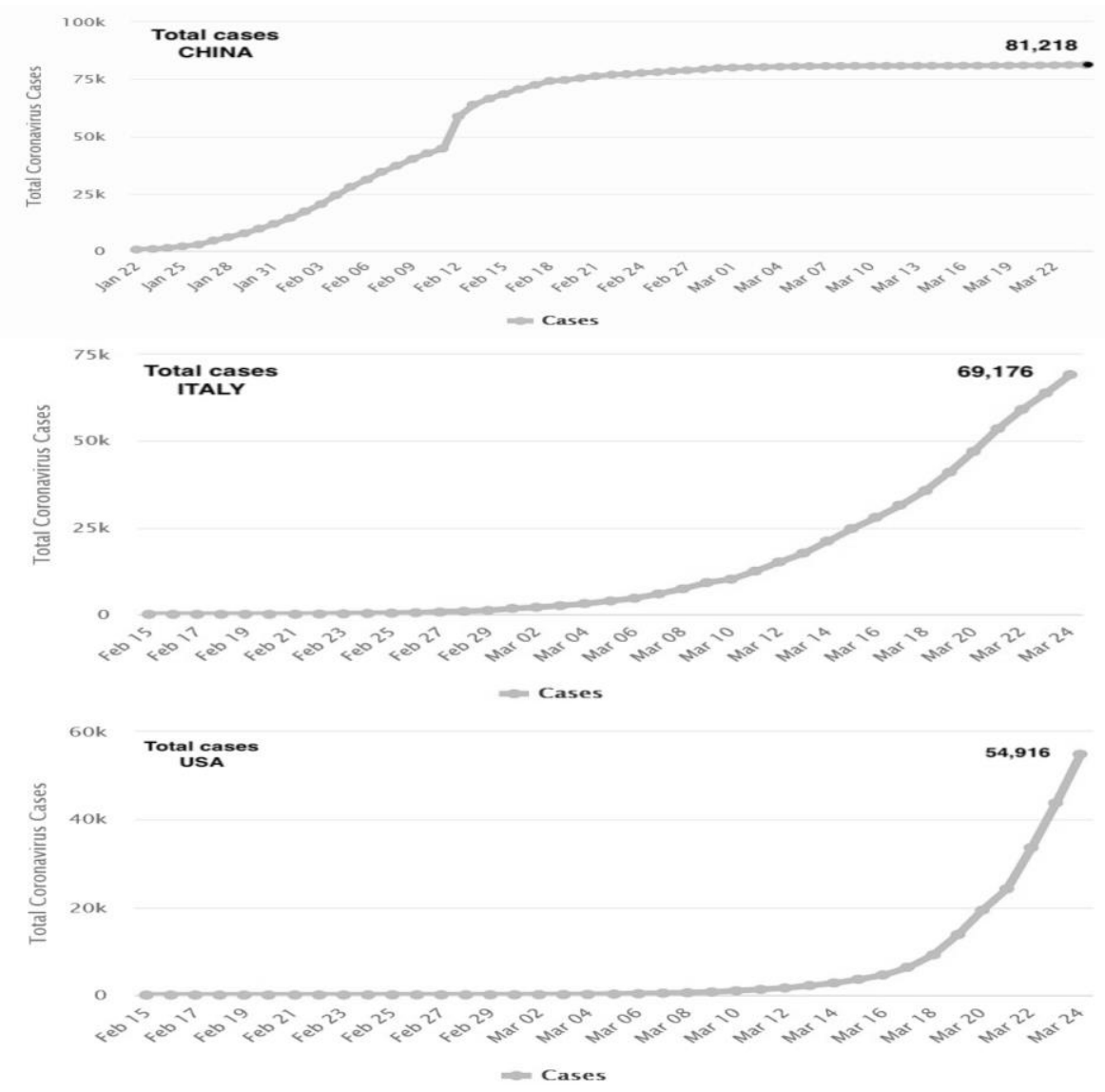

Figure-2. Number of total COVID-19 cases for China, Italy and United States (as on Mar 24, ${ }^{\text {th }}, 2020$ ). Source: www.worldometers.info. 


\subsection{Comparative Daily Cases}

As for China, the number of daily cases reported was highest on February 12, 2020 with 14,108 cases. Lowest cases $(\mathrm{N}=214)$ was reported in the month of February on $23^{\text {rd }}$. In March, 2020, China managed to handle the spread of the virus and the number of daily reported cases decreased as only 40 cases were detected on March 08, 2020 and then only 19 on $9^{\text {th }}$ March Figure 3. Similarly, only 20 new cases were recorded on March 14th 2020.
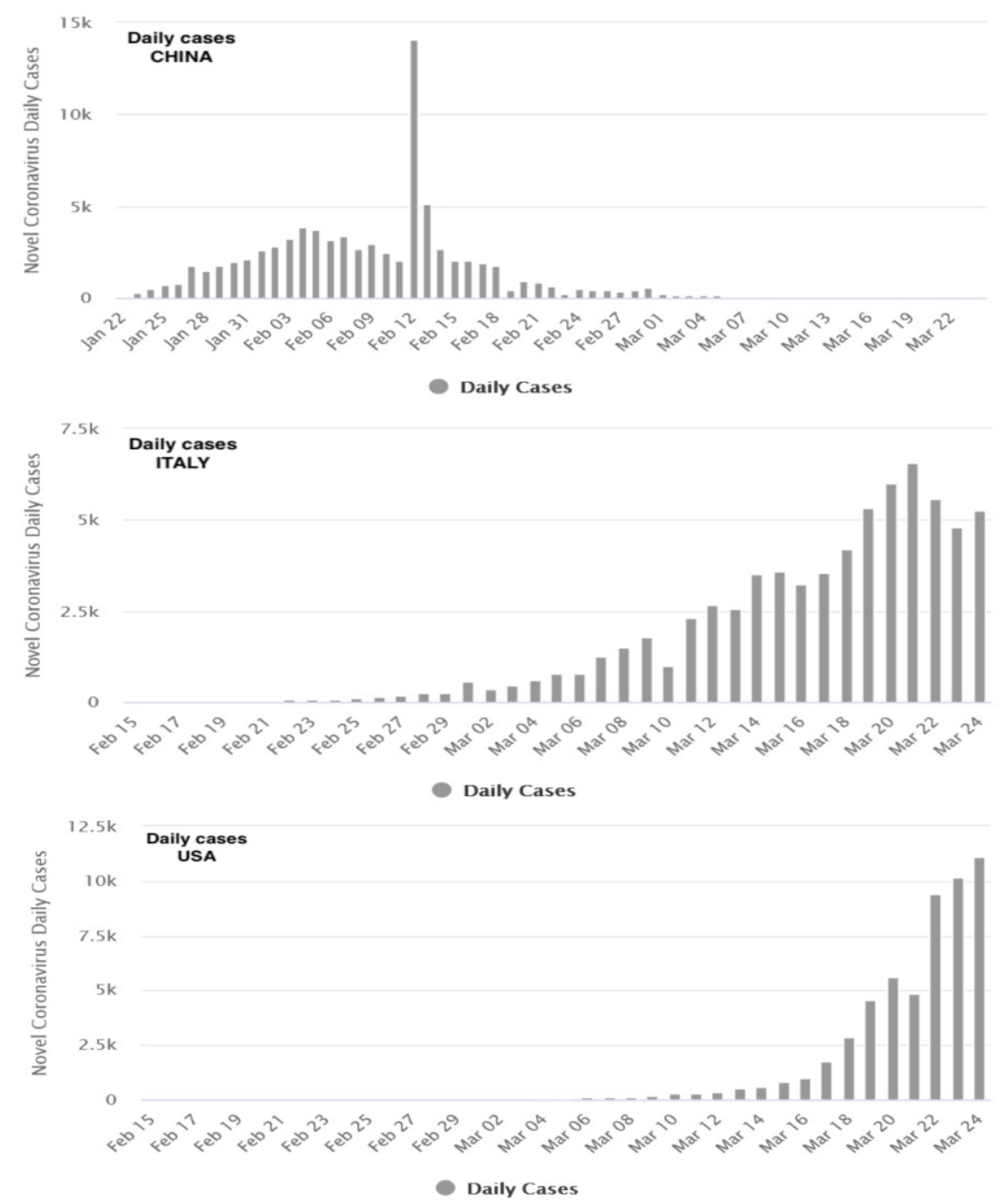

Figure-3. Number of daily COVID-19 cases for China, Italy and United States (Till Mar 24t, 2020). Source: www.worldometers.info.

On the contrary, Italy started with only one case recorded on 28 February, 2020 and then the number of cases increased at a high speed and reached 573 cases on March 1 ${ }^{\text {st }}, 2020$. After this, the number of daily cases recorded increased at a very high rate and the biggest record was 6557 cases on $21^{\text {st }}$ of March. If we compare the curves for daily cases in China and Italy, there was a significant reduction in the number of daily cases in China after $21^{\text {st }}$ of February, 2020, whereas in Italy, it started from $22^{\text {nd }}$ of February. United States on the other hand got a first significant record (Crossing 100) of COVID-19 patients on March $7^{\text {th }}$ with 116 cases. But after that, the number of cases increased enormously with a huge record of 5588 cases on March $20^{\text {th }}, 9400$ cases on March $22^{\text {nd }}$ and 11075 cases for March 24, th and this number may increase in future.

\subsection{Comparative Total Deaths}

China needs appreciation for what they did for their COVID-19 patients. With an enormous number of patients $(\mathrm{N}=81,218)$, the number of recorded deaths as on March 22 $2^{\text {nd }}, 2020$ was 3,281 (Death rate $\left.=0.040\right)$ Figure 4 . It 
clearly demonstrates that China has played all his cards to manage the patients and was successful in getting a recovery record of 73,650 patients. This high recovery rate may include the best possible patient care. If we see Italy, for 69,176 recorded cases, the number of recorded deaths was 6,820 (Death rate $=0.098$ ) with a recovery of only 8,326 patients till 24th March, 2020. But USA, with 54,916 cases witnessed only 784 deaths (Death rate $=$ 0.014).
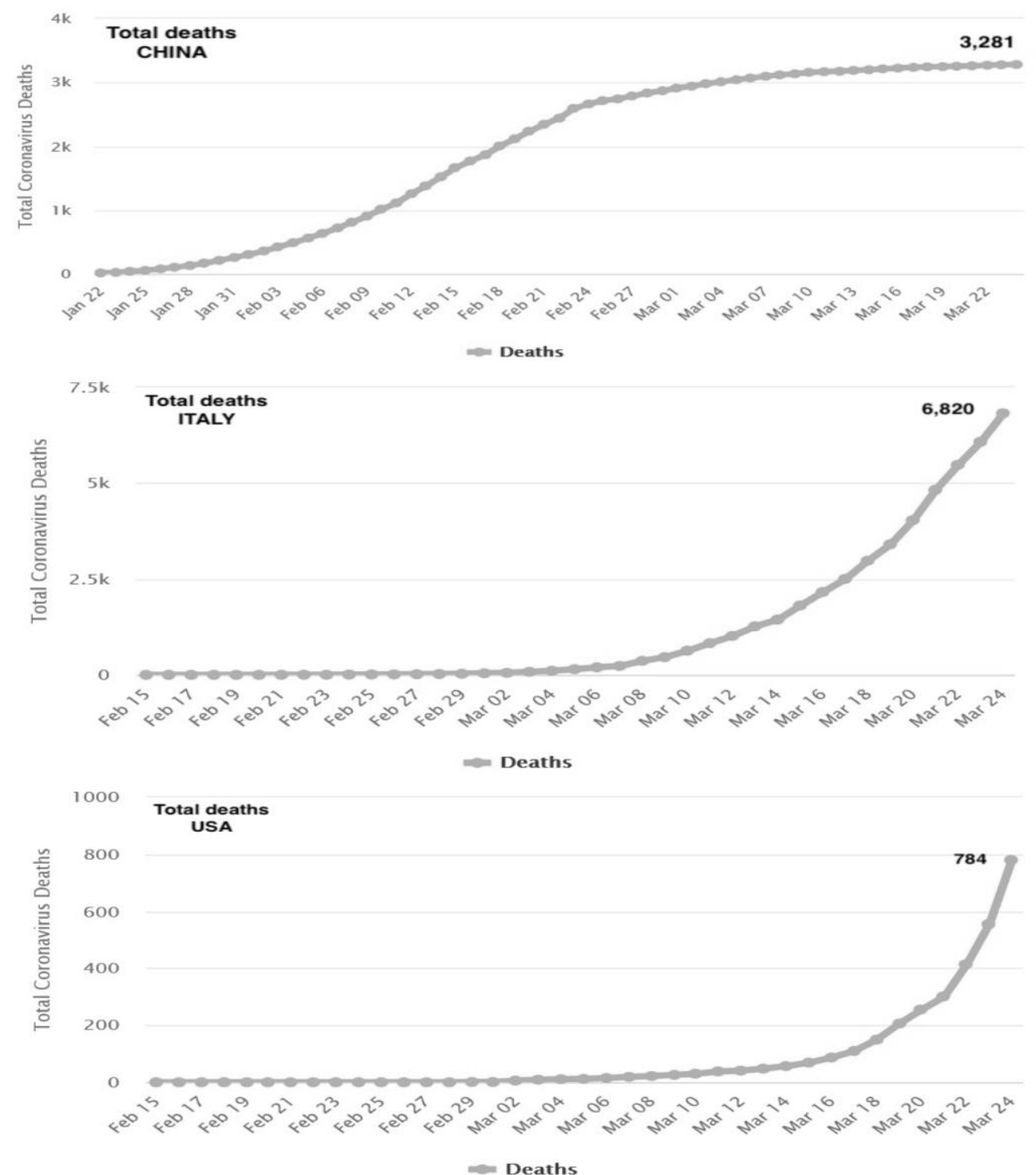

Figure-4. Number of total deaths for COVID-19 patients for China, Italy and United States (as on Mar 24 $4^{\text {th }}, 2020$ ). Source: www.worldometers.info.

Thus, as far as the number of total deaths is concerned, United States is having the lowest death rate of 0.014 followed by China with 0.040 and Italy with 0.098 which is very close to 1 . But here, it is worth mentioning that death rate for USA might increase in future as the number of daily cases is still increasing for USA but for China, it has decreased to very low values. Figure 5 shows the number of daily deaths among three countries. 

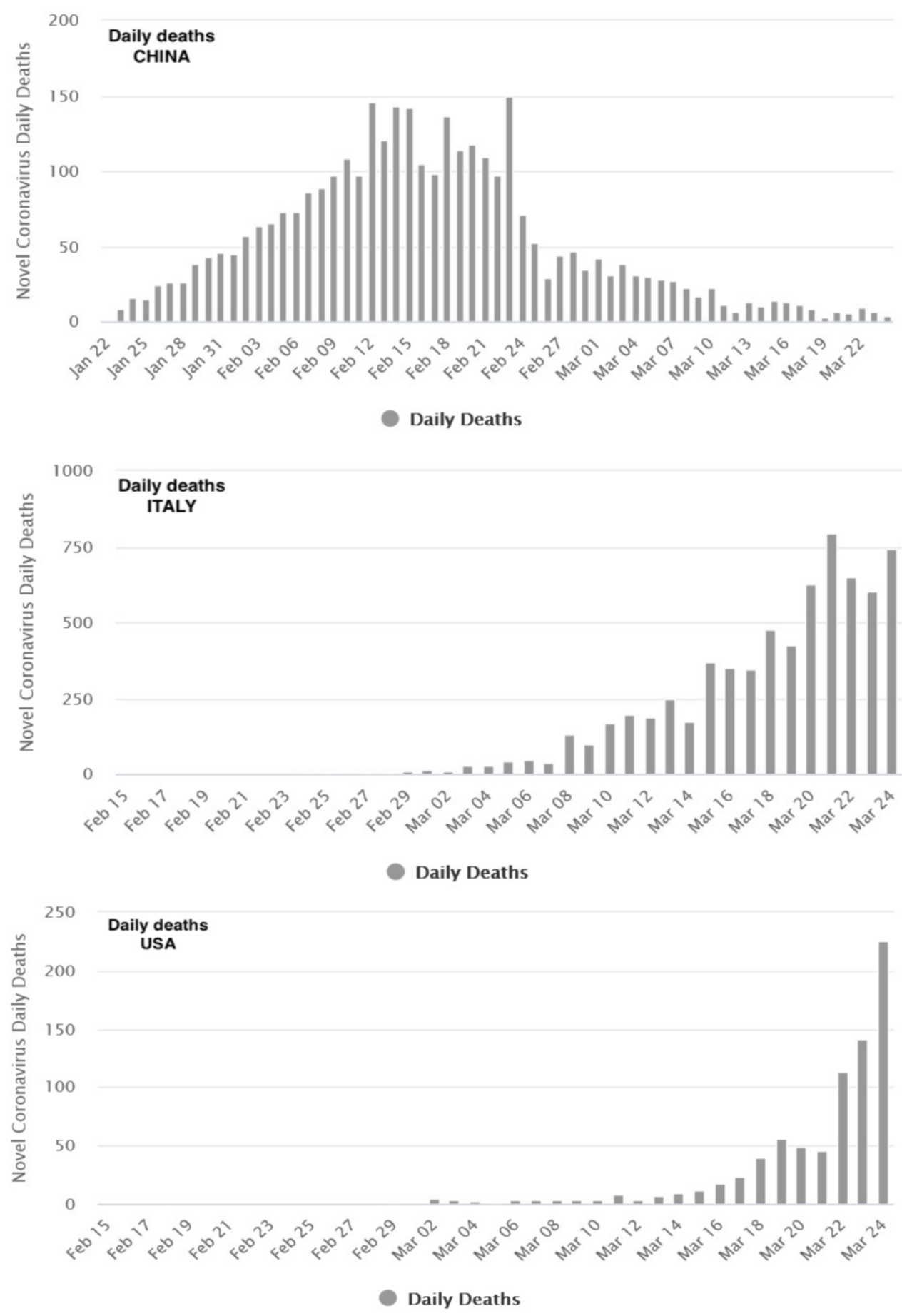

Figure-5. Number of daily deaths for COVID-19 patients for China, Italy and United States (as on Mar 24 $4^{\text {th }}, 2020$ ). Source: www.worldometers.info.

\subsection{Countries with Least Cases}

Figure 1 shows the number of COVID-19 patients the help of blue colour. Countries including Libya, Papua New Guinea, Somalia and Syria are the least affected countries with only 1 recorded confirmed case till March $24^{\text {th }}$, 2020. Table 2 shows the list of the countries with the least number of COVID-19 cases till now. The table also demonstrates the total number of cases for 1 million of population among these countries. This is the lowest for Somalia and Syria with 0.06, followed by Somalia and Papua New Guinea with 0.1. 
Table-2. Countries with least number of COVID-19 cases.

\begin{tabular}{l|c|c}
\hline Country & Cases & Total cases/1M population \\
\hline Belize & 1 & 3 \\
\hline Eritrea & 1 & 0.3 \\
\hline Grenada & 1 & 9 \\
\hline Libya & 1 & 0.1 \\
\hline Montserrat & 1 & 200 \\
\hline Papua New Guinea & 1 & 0.1 \\
\hline St. Vincent Grenadines & 1 & 9 \\
\hline Somalia & 1 & 0.06 \\
\hline Syria & 1 & 0.06 \\
\hline Timor-Leste & 1 & 0.8 \\
\hline Turks and Caicos & 1 & 26 \\
\hline Source: www.worldometers.info. & &
\end{tabular}

\section{CONCLUSION}

COVID-19 has been identified as the cause of an outbreak of respiratory illness in Wuhan, China and the overall number of the COVID-19 cases is increasing worldwide. On early stages in the COVID-19 cases growth chart, the absolute difference remains small, but over time the exponential growth leads to very large numbers for many countries. As on 24th March, 2020, China, Italy and United States were found to be the countries with maximum number of reported cases of COVID-19. China seemed to manage this outbreak with only 3281 deaths for 81,218 cases with a death rate of 0.040 and a recovery record of 73,650 patients. This high recovery rate may be the result of great vigilance and good medical services. In Italy, for 69,176 recorded cases, the number of recorded deaths was 6,820 (Death rate $=0.098$ ) and for USA with 54,916 cases the number of death records was 784 deaths with a death rate of 0.014 which can still increase as USA has a large number of active cases. COVID-19 is affecting globally at a very high pace and should be dealt with maximum efforts by all the countries.

Funding: This study received no specific financial support.

Competing Interests: The author declares that there are no conflicts of interests regarding the publication of this paper.

\section{REFERENCES}

[1] Q. Ahmed and Z. Memish, "The cancellation of mass gatherings (MGs)? Decision making in the time of COVID-19," Travel Medicine and Infectious Disease, vol. 34, p. 101631 , 2020.Available at: 10.1016/j.tmaid.2020.101631.

[2] S. P. Adhikari, S. Meng, Y.-J. Wu, Y.-P. Mao, R.-X. Ye, Q.-Z. Wang, C. Sun, S. Sylvia, S. Rozelle, and H. Raat, "Epidemiology, causes, clinical manifestation and diagnosis, prevention and control of coronavirus disease (COVID-19) during the early outbreak period: A scoping review," Infectious Diseases of Poverty, vol. 9, pp. 1-12, 2020.

[3] P. Adepoju, "Nigeria responds to COVID-19; first case detected in Sub-Saharan Africa," Nature Medicine, vol. 26, pp. 444-448, 2020.Available at: 10.1038/d41591-020-00004-2.

[4] A. A. Agyeman, A. Laar, and R. Ofori-Asenso, "Will COVID-19 be a litmus test for post-Ebola Sub-Saharan Africa?," Journal of Medical Virology, pp. 1-3, 2020.Available at: https://doi.org/10.1002/jmv.25780.

[5] T. Ahmad, M. Khan, T. H. M. Haroon, S. Nasir, J. Hui, D. K. Bonilla-Aldana, and A. J. Rodriguez-Morales, "COVID19: Zoonotic aspects," Travel Medicine and Infectious Disease, 2020.Available at: 10.1016/j.tmaid.2020.101607.

[6] T. Ai, Z. Yang, H. Hou, C. Zhan, C. Chen, W. Lv, Q. Tao, Z. Sun, and L. Xia, "Correlation of chest CT and RT-PCR testing in coronavirus disease 2019 (COVID-19) in China: A report of 1014 cases," Radiology, vol. 296, pp. E32-E40, 2020.Available at: 10.1148/radiol.2020200642.

[7] M. A. Al-Qaness, A. A. Ewees, H. Fan, and M. Abd El Aziz, "Optimization method for forecasting confirmed cases of COVID-19 in China," Journal of Clinical Medicine, vol. 9, p. 674, 2020.Available at: 10.3390/jcm9030674.

[8] J. A. Al-Tawfiq, A. H. Al-Homoud, and Z. A. Memish, "Remdesivir as a possible therapeutic option for the COVID19," Travel Medicine and Infectious Disease, vol. 34, p. 101615, 2020.Available at: 10.1016/j.tmaid.2020.101615. 
[9] J. A. Al-Tawfiq, "Asymptomatic coronavirus infection: MERS-CoV and SARS-CoV-2 (COVID-19)," Travel Medicine and Infectious Disease, vol. 35, p. 101608, 2020.Available at: 10.1016/j.tmaid.2020.101608.

[10] Z. Allam and D. Jones, "On the coronavirus (COVID-19) outbreak and the smart city network: Universal data sharing standards coupled with artificial intelligence (AI) to benefit urban health monitoring and management," Healthcare, vol. 8,2020 .

[11] WHO Director-General's Opening Remarks, "Retrieved from: https://www.who.int/dg/speeches/detail/whodirector-general-s-opening-remarks-at-the-media-briefing-on-covid-19---3-march-2020," 2020.

[12] Coronavirus Cases, "Retrieved from: https://www.worldometers.info/coronavirus," 2020.

Views and opinions expressed in this article are the views and opinions of the author(s), Journal of Diseases shall not be responsible or answerable for any loss, damage or liability etc. caused in relation to/arising out of the use of the content. 